\title{
Role of Literature in Teaching English as Foreign Language Context
}

\author{
Xuewei Gong1,* \\ ${ }^{1}$ School of Foreign Language, Yunnan Normal University, Kunming, Yunnan, China \\ *Corresponding author. Email: 547871944@qq.com
}

\begin{abstract}
To enable students to master a language better, literature as a teaching tool, plays a very important role. This article offers the author's insight into the importance of literature in teaching English context. But, for English as foreign language students, engagement as an effective method in literature learning also has its barriers. This paper tries to discover the ways of learning and teaching literature to overcome the barriers of engagement with literature in Chinese EFL context by analyzing a literary work. Students should understand and analyze the linguistic, literary, and cultural abilities of context in learning literature. And the teacher should focus on designing the teaching curriculum and selecting appropriate literary text for the students.
\end{abstract}

Keywords: Literature; Language; Engagement; Teaching; Context

\section{INTRODUCTION}

In China, literature is regarded as one of the most important teaching tools for students to access the target culture. As a teaching tool, literature can be used in conjunction with the communicative approach for EFL students (Li Mingsheng, 1997). However, literature is not only as tool for teaching language, but as a reservoir of ideas, emotions and experiences reflected varied human experiences in the world. Studying literature in context means to study the others' cultures, so learners will have an opportunity to develop their communicative competence and language proficiency to cope with people in cross-cultural encounters. In addition, learning literature in context can further broaden learners' perspectives in both imagination and creativity.

\section{ENGAGEMENT WITH LITERARY TEXTS IN EFL CONTEXTS}

English literature is taught in Chinese foreign language classroom for many reasons. The most common ones are that literature provides easy access to interesting content materials and cultural background. To EFL students, engagement is undoubtedly vital in effective and successful learning of English literature. But how to define 'engagement'? Reed and Schallert (1993) discuss the term 'involvement', and Nystrand and Gamoran (1991) differentiate between 'procedural engagement' and 'substantive engagement' (Smith. 2000). The context of the literary act and the culture of the classroom play a substantial role in engagement to reading. Students are more engaged in the literary act when provided with the opportunity to respond to and challenge each other's interpretations, challenge the author's style, share their opinions about text and question the meaning of the text. Literature has an important role in that it helps students commit to learning and become more substantively engaged. Of course, there are many barriers to engagement for Chinese students reading English texts.

\section{BARRIERS TO ENGAGEMENT WITH LITERATURE TEXT IN EFL CONTEXTS}

The Chinese students lack cultural, linguistic and literary competence that make it difficult to engage in English literature.

\subsection{Cultural}

Culture contains way of speaking, idiom, and beliefs. Language learning and culture learning is well integrated through literature. English literature requires that students analyze the text according to cultural knowledge what they know to improve their language and socio-culture competence.

\subsection{Linguistic}

The second barrier of learning English literature in China is the student lack of linguistic ability to decode literary meaning in literature. Someone unacquainted with literature, would be quite baffled if presented with a poem. Although his knowledge of the language would enable him to understand phrases and sentences, he would not know quite literally. He has not internalized the grammar of literature, which would permit him to convert linguistic sequences into literary structures and meanings. 


\subsection{Literary}

Because of different cultural and linguistic information, literary language is equally the biggest barrier to engagement with literary texts in EFL contexts. English literature is difficult to engage in. Although many Chinese teachers have fears about literature teaching and learning (because of the cultural differences, background, linguistic difficulties and literary deficiencies are also equally the barriers to EFL teachers in learning and teaching literature, after all, English is not their mother tongue.), others are good at teaching literature. Literature teaching can develop the students' analytical abilities. The teacher is the sole authority in the classroom. Therefore, the teacher has an important role in helping EFL students to learn English literature. What can the teacher do to avoid/overcome the above barriers to promote engagement with literature in EFL contexts? The researcher thinks that selecting an appropriate literary work is the key link in promoting engagement with literature in EFL contexts; moreover, it also is the first step for motivating the students' engagement with literary texts.

\section{METHODOLOGY}

In this article, the focus is to discover the ways of learning and teaching literature to help students overcome barriers of engagement with literature in contexts. Therefore, the researcher chooses a literary work "Cat in the Rain" by Ernest Hemingway to be an example about the stages of literature learning. First of all, the theme of this work is universal in nature- "need", the cat is a symbol of anger, a common emotion for all people. The cat symbolizes women. The work also discusses the relationship between man and woman. In this social background, the man holds the power, and the woman seems to have little control over her direction. In China, this kind of social background and relationship has existed for thousand years, even today. So the students can relate to the themes of this work, and perhaps, they have been in this kind of relationship. Second, much of the vocabulary is familiar. Third, the syntax of this work is more likely to be similar to that which is encountered in language textbooks. Fourth, the language is not dated. Finally, this is the short story, and the style is very simple, therefore, the students can understand the meaning easily.

\section{DISCUSSION}

The following is a plan for classroom activities:

- Pre-Activity. In this stage the researcher will write the title of the work and the questions on the blackboard to build up interest in the work and get the students to anticipate what they will read about. This is a time for them to guess and predict.

Title: Cat in the Rain

Questions:
1) Discuss how cat feels about rain and how we feel about rain.

2) Will the story be about a cat?

3) Will someone lose his/her cat?

4) Think about and say some vocabulary words about both cat and rain.

- Analysis. The students can read the story silently first, and then think about the following surface-level questions, e.g.,

1) How many people were in the story?

2) Where was the couple?

3) Did she get the cat?

In this stage, the main purpose is to check whether the students have understood the basic plot.

- Response. Using response in the classroom can have a profound impact on how students view the work and how they see their role as readers. Rather than relying on a teacher or critic to give them a single, standard interpretation of a work, students learn to construct their own meaning by connecting the textual material to issues in their lives and describing what they experience as they read. As a teacher, try to make the students in the classroom become active learners.

This is the stage of interpretation and evaluation. The aim of this stage is for the students to react to the work, construct meaning from it, and discuss their ideas with each other. Traditionally, the teacher asks questions such as:

How does the writer feel about the husband and the hotel keeper?

Why does the wife feel such sympathy for the cat?

Have the students discuss these questions in groups, because it allows more students the chance to participate. Of course, discussing questions is not the only way of conducting this stage. The teacher should also motivate and encourage the students to refer to the work as much as possible.

\section{CONCLUSION}

Teaching English literature in China can help students acquire the language and facilitate their social and cultural competence. But as discussed in this paper, there are barriers to engagement with literature in EFL contexts in China. This paper argues that, to address these barriers, students should pay more attention to engaging understanding and analyzing the linguistics, literary and cultural capabilities of text in learning English literature. The teacher should pay careful attention to designing the English literature teaching curriculum and syllabus, selecting appropriate literary texts for the students. Additionally, the teacher should focus on fostering students' social cultural, linguistic and literary competence.

\section{REFERENCES}

[1]Alptekin, C.. Target-language Culture in EFL materials, ELT Journal 47(2), 1993. 
[2]Li Mingsheng. English literature teaching in China: Flowers and Thorns. The Weaver: A Forum for New Ideas in Education, 1997.

[3]Nystrand, M. and Gamoran, A.. Instructional discourse, student engagement and literature achievement Research in the Teaching of English, 1991.
[4]Schallert, D.. The nature of involvement in academic discourse tasks Journal of Educational Psychology, 1993.

[5]Smith Erica M.. The Notion of Engagement - a brief review of the literature. Negotiating Barriers to Engagement with English Literature in a Chinese EFL Context, 2000. 